\title{
Adayların Yansıtıcı Günlüklerinde Öğretmenlik Uygulamasına Yönelik Farkındalıkları
}

Mehmet Metin ARSLAN, Doç. Dr., Kırıkkale Üniversitesi Eğitim Fakültesi, mehmetmetinarslan1@gmail.com ORCID: http://orcid.org/0000 000345971970

Öz: Öğretmen adaylarına, gerek kuramsal gerekse uygulamalı dersler verilerek meslekî yeterlikleri kazanmaları sağlanmaktadır. Adayların mesleki uygulamalarla öğretmenliğe yönelik farkındalık geliştirmeleri; mesleğe yönelik olumlu tutum edinmelerinde önemli bir etkiye sahiptir. Bu durumun bir deneyim kazanma ve paylaşma süreci olduğudüşünüldüğünde adayların yaratıcı, eleştirel düşünmelerini destekleyen yansıtıcı günlük çalışmaları önem kazanmaktadır. Bu çalışmada pedagojik formasyon eğitimi sertifika programına katılan öğretmen adaylarının öğretmenlik uygulama süreçlerine yönelik farkındalıklarının yansıtıcı günlükler aracılığıyla belirlenmesi amaçlanmıştır. Araştırma 30 katılımcı ile gerçekleştirilmiş ve çalışma grubundan verilerin toplanmasında nitel araştırma yaklaşımlarından biri olan doküman incelemesi kullanılmıştır. Yapılan analiz sonucunda öğretmen adaylarının kendi öğretme süreçlerine ilişkin farkındalık düzeylerinin oldukça düşük olduğu tespit edilmiştir.

Anahtar Kelimeler: öğretmen adayı, formasyonsertifika programı, yansıtıcı günlükler.

\section{Awareness of Candidates on Teaching Practice in Their Reflective Diaries}

\begin{abstract}
Prospective teachers are taught with theoretical and practical courses in order to obtain professional qualifications. Development of awareness by candidates on teaching through occupational practice has a significant impact on them to gain positive attitude towards the occupation. Reflective diary study that supports candidates' creative, critical thinking is important when it is considered as a process of gaining and sharing experience. In this study, it was aimed to determine the awareness of prospective teachers participating in the formation certificate program on teaching practice processes through reflective diaries. The research was carried out with 30 participants and a document review, one of the qualitative research methods, was used to collect data from the study group. As a result of the analysis, it was determined that prospective teachers' awareness levels about their own teaching processes are very low.
\end{abstract}

Key Words: prospective teacher, formation certificate program, reflective diaries 


\section{GiRiş}

Öğretmenlik, bireyin kendine yönelik farkındalığının en üst düzeyde olmasını gerektiren mesleklerin başında gelmektedir. Bu nedenle "Öğretmen Eğitimi" bileşeni kapsamında, öğretmenlik uygulaması sürecinde adayların bireysel özelliklerini görmeleri, geliştirmeleri ve kullanmaları gibi üst düzey becerileri yerine getirebilmeleri için kendi yapabilecekleri hakkında bilgi sahibi olmaları beklenmektedir. Öğretmen adaylarının, mesleğe daha iyi hazırlanmaları için pedogojik formasyon eğitimi süresince kazandıkları öğretmenlik mesleğiyle ilgili bilgi, beceri, tutum ve alışkanlıklarını gerçek bir eğitim-öğretim ortamı içinde kullanabilme yeterliliği kazanmalarını sağlayacak uygulama çalışmalarına katılmaları gerekmektedir. Bu uygulama çalışmalarının daha iyi nasıl olabileceği sorusu, öğretmenlik mesleği ve öğretmen yetiştirme süreci açısından en çok tartışılan konular arasında yer almakta ve özellikle öğretmenlerin hizmet öncesi eğitimleri sürecinde kuram ve uygulama yaklaşımlarına yoğunlaşmaktadır (Sarıtaş, 2007; Nayır ve Çınkır, 2014; Nakip, 2015; Ünver, 2016). Dolayısıyla öğretmenlik mesleğinde teorik bilginin yanı sıra uygulamanın da oldukça önemli olduğu söylenebilir. YÖK'ün (2015) yayımladığı pedagojik formasyon eğitimi sertifika programları hakkında açıklaması da bu noktayı vurgulayarak uygulamaların uzun bir süreci kapsaması gerektiğini ifade etmektedir:

Gelişmiş ve gelişmekte olan ülkelerde öğretmen adayı yetiştirme programları incelendiğinde, hizmet öncesi eğitim süresi yönünden kuramsal eğitimleriçin ayrılan süre kadar okullarda yapılan uzun süreli gözlem ve uygulamalar da önem kazanmaktadır.

$\mathrm{Bu}$ ifadelerden de anlaşılacağı gibi her meslek grubunda olduğu gibi öğretmenlik mesleğinde de mesleki uygulamayla farkındalıkların hissedilmesi mesleğe yönelik olumlu tutum geliştirmede ve verimliliği artırmada önemli bir etkiye sahiptir.

Öğretmen adaylarının meslek hakkında gerekli donanımı edinmeleri ve mesleğin saygınlığı konusunda bilinçlenmeleri için özellikle öğretmenlik uygulaması derslerinde bir farkındalık oluşturmak gerekmektedir. Öğretmen adaylarının aldıkları gerek kuramsal gerekse uygulamalı dersler kapsamında meslekî yeterliklerini keşfetmelerine yardımcı olunmalıdır. ifade edilen öneri doğrultusunda yapılabileceklerden biri yaratıcı, eleştirel düşünmelerini destekleyen günlüklerden faydalanma olabilir. Hem öğrenme hem de öğretme süreçlerine yönelik ne yapıp yapmadıkları noktasında günlüklerin birer rehber olacağı belirtilebilir. Özellikle bu günlükler, yol gösterici bir nitelik kazandığından yansıtıcı günlük olarak adlandırılabilir. Yansıtıcı günlükler, öğretmen adayları için yararlı bir deneyim alanıdır (Akoyunlu, Telli, Çetin ve Dağhan; 2016). Özellikle "Öğretmenlik Uygulaması" dersinin bir deneyim kazanma ve paylaşma süreci olduğu düşünüldüğünde bu nitelikteki günlüklerin kullanımını sağlamanın önemi bir kez daha anlaşılmaktadır. Uygulama sırasında öğretmen adaylarının kendi güçlü ve zayıf yönlerini anlamlandırmalarında stratejik bir araç özelliği taşımaktadır.

\section{Yansıtıcı Günlükler}

Bireyin kendini yazarak ifade etmesi, üst düzey bir beceridir, dolayısıyla yazma ve düşünme bu süreçte birbiriyle eşgüdüm içerisindedirler. Bütüncül olarak düşünme; çıkarımlar yapma, kavramlar ve önermeler arasında bağlantı kurma (Duman, 2012:353) şeklinde tanımlanabileceği gibi bir sonuca varmak için bilgileri, kavramları incelemek, karşılaştırmak ve aralarında ilişkiler kurarak başka düşünceler üretmek şeklinde de açıklanabilir (MEB, 2007:5). Akkoyunlu vd. (2016), Dewey'in (1933) yaparak yaşayarak öğrenme yaklaşımının yansıtıcı düşünmenin kuramsal temellerini oluşturduğunu ifade etmektedirler.

Düşünme sırasında bireyin kendini yansıttığı dikkate alındığında yansıtıcı düşünme, üst düzey bir düşünme becerisi olarak nitelenmektedir. Bu anlamda yansıtıcı düşünme; bireylerin gerçekleştirdikleri ve planladıkları eylemlerine ilişkin derinlemesine düşünmelerini sağlayarak 
zayıf ve güçlü yanlarının farkına varmalarını, eksikliklerini nasıl gidereceklerine dair fikir edinmelerini, ayrıca kendilerinin ve çevrelerindekilerin çabalarını izleyerek kendilerinin ve diğerlerinin öğrenme ve düşünme süreçlerini anlamlandırmalarıdır (Ersözlü, 2008). Ifade edilen özelliğinden dolayı yansıtıcı düşünme bireysel bir beceri olarak yorumlanabilir.

Yansıtma, deneyimler üzerinde düşünülen ve belirli bir görev dikkate alınarak değerlendirmede bulunulan bir süreçtir (Atay, 2003). Yansıtıcı günlükler ise bireyin öğrenme sürecine yönelik kendi değerlendirmesinin yazılı belgeleri olarak tanımlanmaktadır (Uslu, 2009). Öğretmen adayının kendini izlemesi ve kendisi ile ilgili farkındalığını artırması için yansıtıcı günlüklerden yararlanılabilir. Yansıtıcı günlük kavramı, günlük hayatta kullanılan günlüklerden ayrılmaktadır. Yansıtıcı günlük kullanımının amacı; öğrencinin öğrenme tecrübesini süreç odaklı değerlendirmesini sağlamaktır. Böylelikle öğrenci, sonraki öğrenme süreçleri için bir ön deneyim oluşturacak ve sürecini planlayabilecektir (Malthouse ve Roffey, 2013). Eğitimde yansıtıcı günlüklere yer verilmesinin temel sebebi de bu şekilde açıklanabilir. Bu günlüklerin kullanımında öğrencilere belirli bir eğitim verilmesi, günlüklerin sağıklı bilgi vermesi açısından önemlidir. Bu açıdan yansıtıcı günlük yazımında dikkat edilmesi gereken hususlar şu şekilde sıralanabilir:

1. Öğrenim sürecindeki engeli fark etme

2. Gerçekleştirilen performansın analizini gerçekleştirme

3. Tanımlanan öğrenme sürecindeki performansı artırmak için planlama yapma (Raw, Brigden ve Gupta, 2005).

Ifade edilen bu aşamaların her birinin gerçekleşmesi yazma sürecinde beklenmektedir. Aksi takdirde yansıtıcı günlüklerden elde edilmesi amaçlanan değerlendirme sürecine yeterli düzeyde ulaşılması beklenemez. Yansıtıcı günlüklerle gerçekleştirilecek değerlendirmeler sayesinde öğrencilerin kendi öğrenme süreçlerine yönelik farkındalık düzeylerinin tespit edilebilir (Moon, 2009). Bunun için yansıtıcı yazma seviyeleri belirleyen Moon (2009), bunları detaylı olarak açıklamaktadır (Akt. Melanlıŏlu ve Demir, 2016 ):

Tablo 1

Yansıtıcı Yazma Seviyeleri

Düzey

Davranış

Tanımlayıcı yazma

Biraz yansıtma içeren

tanımlayıcı yazma

Yansıtıcı yazma

Ileri seviye yansıtıcı yazma
Yazma üretimleri, az miktarda yansıtma içerir. Öğrenme sürecine ilişkin değerlendirmeden ziyade öğrenme sürecinde izlenen sıra anlatılmaktadır.

Fazla yansıtma içermeyen üretimlerdir. Genelde soru-cevap şeklindeymiş gibi tanımlamalar içerir. Öğrenme sürecine yönelik analiz yetersizdir.

Sürece ilişkin öğrencinin bir fikri vardır ancak bu fikir bütün bir süreci kapsamamakta, sadece ilgi, dikkat vb. nedenlerle belirli aşamaları içermektedir. Bu aşamalara yönelik öğrencinin süreç için analizleri vardır, yansıtıcı değerlendirmeler yapmıştır, farkındalık oluşmaya başlamıştır. Fakat bu farkındalık belirli aşamalarla sınırlıdır.

Öğrenme sürecini izlemiş, süreçte karşılaştığı problemlerin ortadan kaldırılması için farklı çözüm yolları üretmiş ve buna yönelik bir değerlendirmede bulunmuş günlüklerin yapısıdır. Üretimde derin bir yansıtma vardır ve üst biliş stratejileri aktif olarak kullanılır. Ön bilgi ve 
deneyimler, yeni öğrenmelere rehberlik eder.

Tablo 1 incelendiğinde bireyin hangi aşamada yansıtmayı gerçekleştirdiği önem arz etmektedir çünkü yansıtma düzeyi aynı zamanda bireyin kendine yönelik farkındalığının da bir ölçütüdür. Bu becerileri kullanabilen öğretmen adayı, öğrenme-öğretme sürecinde bağımsız hareket etme olanağına sahiptir.

\section{Çalışmanın Amacı}

Öğretmenlik gibi sorumluluğu yüksek bir mesleği yapacak olan adayların kendilerine, öğretme süreçlerine yönelik farkındalıkları, karşılaşacakları öğrencilere kazandıracakları bilgi ve becerinin de derecesi hakkında bir fikir vermektedir. Bu bağlamda çalışmanın amacı, öğretmen adaylarının öğretmenlik uygulaması dersinde kendi öğretme süreçlerine yönelik farkındalık düzeylerini belirlemektedir. Böylece pedogojikformasyon eğitimi alan öğrencilerin, mesleğe ilişkin eksikliklerini fark etmeleri, kendi gelişimlerini gözlemlemeleri sağlanmış olacaktır.

\section{YÖNTEM}

Bu bölümde araştırmanın deseni, çalışma grubu, veri toplama aracı ve verilerin analizine ilişkin bilgiler bulunmaktadır.

\subsection{Araştırmanın Modeli}

Araştırma amacına uygun olarak elde edilecek verilerin sağlanmasında nitel araştırma yaklaşımlarındanbiri olan doküman incelemesi kullanılmıştır. Doküman incelemesi, var olan kayıt ve belgeleri inceleyerek veri toplanmasına odaklanmaktadır. Bunun için araştırılan olguya en yakın belge ve kanıtlar bu kapsamda incelenmektedir (Yıldırım ve şimşek, 2008). Bu araştırmada öğretmen adaylarının yazılı üretimlerinde öğretme süreçlerine yönelik farkındalıkları ortaya çıkarılmak istendiği için öğretmen adaylarının ürettikleri metinler, doküman olarak ele alınmıştır.

\section{2 Çalışma Grubu}

Nitel olarak desenlenen araştırmanın katılımcılarını, Kırıkkale Üniversitesi Eğitim Fakültesi bünyesinde 2015-2016 öğretim yılında açılan Pedagojik Formasyon Eğitimi sertifika programına katılan ve Öğretmenlik Uygulaması dersini alan gönüllü 30 öğretmen adayı oluşturmaktadır. Çalışmadaki amaç katılımcı görüşlerinin derinlemesine ortaya konması olduğu için kişisel değişkenler araştırma kapsamında değerlendirilmemiştir.

\subsection{Verilerin Toplanması}

Verilerin toplanması aşaması, sekiz haftalık bir süreci kapsamıştır. Gönüllü öğretmen adaylarından Öğretmenlik Uygulaması kapsamında anlattıkları derslere ilişkin birer yansıtıcı günlük oluşturmaları istenmiş; sekiz haftanın sonucunda bu günlükler, katılımcılarla birlikte değerlendirilmiştir.

\subsection{Verilerin Çözümlenmesi}

Elde edilen verilerin analizini sağlamak için içerik analizi kullanılmıştır. İçerik analizinde temelde yapılan işlem, birbirine benzeyen verileri belirli kavramlar ve temalar çerçevesinde bir araya getirmek, kuramsal bilgilerden ya da kişisel bilgilerinden yararlanılarak temalar oluşturmak, böylece verileri toplamadan önce bir kod listesi elde etmektir (Yıldırım ve Şimşek, 2008).Bu kapsamda Moon'un (2009) yansıtıcı günlüğün aşamalarına ilişkin yaptığı tasnif, içerik analizindeki temaların oluşumunda temel unsur olarak değerlendirilmiştir. Bunun temel sebebi, çalışma grubundaki öğrencilerin kendi öğretmenlik uygulaması süreçlerine ilişkin ne 
düzeyde olduklarını belirlemek çalışmanın amacını teşkil ettiği için her bir yansıtma düzeyi, bir tema olarak oluşturulan günlüklere yansımıştır.

İçerik çözümlemesine dayanan bu araştırmada elde edilen verilerin temalara ve bu temaların ölçütlerine uygun olarak yerleştirilmesi gerekir. Dolayısıyla katılımcıların metinlerini puanlama değil, temalara ve ölçütlere göre çözümleme işlemi gerçekleştirilmiştir. Sayısal değerler puan değerini değil kaç kez görüldüğüne gönderimde bulunmaktadır. Yıldırım ve Şimşek'e (2008) göre böyle araştırmalarda güvenirliği sağlayabilmek için elde edilen verilerin çözümlenmesinde bir başka araştırmacıyı kullanma ve sonuçları onaylatma (teyit ettirme) stratejisinden yararlanılabilir. Bu bağlamda oluşturulan değerlendirme yönergesine göre her bir öğrenci metni önce ayrı ayrı iki alan uzmanı tarafından değerlendirilmiştir. Ardından her iki uzmanın öğretmen adaylarının metinlerinin tutarlılığına ilişkin metinsel eylemlerin gerçekleşme düzeyine yönelik kararları karşılaştırılmış; her ikisinin de değerlendirmelerinin paralellik gösterdiği, kodlama güvenirliği oranının $\% 78$ olmasından anlaşılmışır. Bu durum değerlendiriciler arasındaki tutarlılığa dolayısıyla da değerlendirmenin güvenirliğine işaret etmektedir.

Çalışmaya katılan 30 öğretmen adayına isimlerine ve cinsiyetlerine bakılmaksızın birden otuza kadar numara verilmiştir. Örnek ifadelerin yanında bulunan numaralar katılımcılara ait numaralardır (K1: Görüşleri alınan birinci öğretmen adayı gibi.).

\section{BULGULAR}

Araştırma kapsamında toplanan verilerin analizi sonucunda ulaşılan bulgular, öncelikle genel bir tablo ile gösterilmiş, daha sonra tabloda yer alan her bir düzey için katılımcı ifadelerinden örnekler sunulmuştur.

Tablo 2

Öğretmen Adaylarının Yansıtıı Yazma Seviyelerini Gerçekleştirme Oranı

\begin{tabular}{lcc}
\hline \multicolumn{1}{c}{ Düzey } & N & $\%$ \\
\hline Tanımlayıcı yazma & 21 & 70 \\
Biraz yansıtma içeren tanımlayıcı yazma & 5 & 16,7 \\
Yansıtıcı yazma & 3 & 10 \\
ileri seviye yansıtıcı yazma & 1 & 3,3
\end{tabular}

Tablo 2 incelendiğinde katılımcıların \% 70 ( $n=21)^{\prime}$ inin ilk düzey olan tanımlayıcı yazma boyutunda olduğu görülmektedir. Biraz yansıtma içeren tanımlayıcı yazma düzeyinde $\% 16,7$, yansıtıcı yazmada \% 10, ileri seviye yansıtıcı yazma seviyesinde ise $\% 3,3$ katılımcı yer almaktadır.

Yansıtıcı yazmanın ilk düzeyi olarak adlandırılan tanımlayıcı yazma örnekleri katılımcıları ifadeleri ile şu şekilde örneklendirilebilir:

Derse Atatürk'ün kadın haklarına verdiği önemi anlattım. Türklerin tarihine baktığımızda çok önemli ve saygın bir yeri olduğunu görürüz diyerek kadından başladım, seçme ve seçilme hakkından bahsettim, belediye başkanlığı hakkından, muhtarlık hakkından gibi konuları anlattım. Bir arkadaşımız soru sordu pek fikrim olmasa da açıkladım ve usta bir hamleyle peki bende size bir soru sorayım dedim sorumu sordum eğlenceli bir şekilde 
yanıtladılar. Sizlere etkinlik yapacağım dedim ve Görüş Geliştirme tekniğini uyguladım. Günümüzde kadın haklarına değer veriliyor mu verilmiyorsa neden gibi sorularla katılıyorum, katılmıyorum, kararsızım gibi kartonları dağıttım çok eğlendiler fikirlerini söylediler bu şekilde herkes birbirinin fikrine saygı göstererek açıklamalarını yaptılar. Eksiklerime gelecek olursak arkadaşlarım göz teması az kurduğumu söyledi ve bazen dersi anlatırken dışarıya baktığımı belirttiler bende bunlara dikkat ederek bir dahaki ders anlatımımda bunları en aza indirdim ve yapmadım (K 2).

K2'nin derste izlediği sırayı yansıtıcı günlüğüne taşıdığı görülmektedir. Bir uygulama yaptığını ifade etmekte ancak bunu neden gerçekleştirdiğini belirtmemektedir. Yine yeteri kadar bilgi sahibi olmadığı bir soruyu cevaplama durumunda kaldığında nasıl bir yol izlediği de belli değildir. Dolayısıyla K2, tanımlayıcı yazma düzeyindedir, kendi öğretme sürecine yönelik farkındalığı da yetersizdir, denilebilir.

Derste anlatılanların pekiştirilmesi ve öğrencilerde kalıclık sağlaması adına dersin son 10 dakikasında etkinlikler yapılır. Etkinlikler sonucu öğrencilerin anlamadığı yerler tekrar açıklanır. Ve dersin son dakikalarında konu ile ilgili genel bir özet-değerlendirme yapılmıştır. (K29)

Yukarıdaki örnek tanımlayıcı yazmanın daha açık bir örneğidir. K29'un öğretme sürecine ilişkin bir değerlendirmesi söz konusu değildir.

İkinci düzey olan biraz yansıtma içeren tanımlayıcı yazmaya ilişkin katılımcı ifadeleri şöyledir:

ilk deneyimim olacaktı ögretmenlik mesleğinde, tabii ilkler her zaman heyecanlandırır insanı. Ders anlatmadan bir hafta önce başladı telaşım. Konum ne olacaktı, nasıl anlatacaktım, öğrencilere ilk hitabım nasıl olacaktı, nerede duracaktım, ne yazacaktım... Ders anlatacağım gün daha da heyecanlıydım. Ders anlatmaya başlamadan önce kendimi tanıttım ve öğrencilerin dikkatini derse toplamak için derse bir hikâyeyle başladım ve başarılı da oldum. Hikâyeyi okurken heyecandan sesimin titrememesi için de bir hayli çaba sarf ettim. Hikâyeyi okuyup ögrrencilere birkaç soru sorduktan sonra heyecanımı bastırmayı başardım. Âşık edebiyatının nazım şekil ve türlerini tanımlarken öğrencilerin derse katılımı iyiydi ve verdiğim örneklere genelde doğru cevabı verdiler ve dersin sonunda çok beğendiklerini söylediler bu da beni çok mutlu etti. Dersten sonra videoyu izlediğimde kendimde bulduğum eksiklik tahtayı hiç kullanmamış olmamdı. Âşık edebiyatı nazım türlerini, özelliklerini keşke yazsaydım fakat heyecanlanıp yanlış yapmaktan korktum. Heyecanımı çok belli etmemişim buna da sevindim. Hayatımda hiç unutamayacağım bir anı ve tecrübeydi benim için. Bu tecrübe ve öğrencilerin yaklaşımları bu mesleği yapmam konusunda beni daha da cesaretlendirdi ve meslek hayatımda başarılı olacağıma inandırdı. (K8)

K8'in oluşturduğu yansıtıcı günlükten alınan yukarıdaki bölümün düzey olarak biraz yansıtma içeren tanımlayıcı yazmayı kapsadığı söylenebilir. Katılımcının öğrenme sürecine ilişkin kaygılar taşıdığı ve bunları ortadan kaldırmak için çeşitli yollar denediği anlaşılmaktadır.

Bir başka örnek ifade $\mathrm{K} 25^{\prime}$ ten alınmıştır. $\mathrm{K} 25$, ders işlerken izlediği yolun verimli olduğunu düşünmektedir ancak nedeni belli değildir:

Çocuklardan Edat dediğimde ne anladıklarını, Bağlaç dediğimde ne anladıklarını ve Ünlem dediğimde ne anladıklarını kelimenin kendisinden veya kökünden yola çıkarak düşünmelerini istedim. Örneğin Bağlaç dediğimde "Bağlamak" cevabını verdiler. Benim amacım da zaten buydu. Kelimeyi somutlaştırıp akıllarında kalmasını sağlayarak örneklerle pekiştirmek istedim bu kısa sürede amacıma ulaştığımı düşünüyorum. Konuyu bu şekilde onlarla birlikte soru cevap tarzında işleyerek dersi tamamladım. (K25) 
Yansıtıcı yazma, üçüncü düzey şeklinde nitelenmektedir. Bu düzeydeki örnek ifadeler şu şekilde sıralanabilir:

Ezber sistemine karşı olduğum için bu anlatacağım konu öğrencilerin aklında nasıl daha iyi kalır onun için çabaladım. Konumu daha çok soru sorarak işledim, anlattığım konuyu gündelik hayatla bağdaştırmaya çalıştım. Fazla sakindim. Bol bol örnek çözdüm. Listeden rastgele isim seçerek öğrencilere sorular yönelttim. Öğrencileri biraz sıktım sanırım. Öğrencilere bir öğretmen gibi değil de öğrenci gibi davranmayı biraz abartmış olabilirim Daha iyi olabileceğimi düşünüyorum. Bilgi birikimi ve tecrübe kazanmam gerekiyor. Daha çok uygulama yaparsam bu eksikliklerimi giderebileceğimi düşünüyorum. (K17)

Yukarıdaki örnek incelendiğinde katılımcı süreçte ne yapıp ne yapmadığııın farkındadır ve yapmadıklarını nasıl yapar konuma gelebileceği konusunda da bir fikri vardır.

Son aşama ileri seviye yansıtıcı yazmadır. Bu aşamayı gerçekleştirebilen kişi, üst düzey düşünme becerilerini aktif olarak kullanabilmektedir.

Illeri seviye yansıtıcı yazma düzeyinde 1 katılımcı bulunmaktadır. Katılımcı sürece yönelik kendini sadece olumlu taraflarıyla değerlendirmemekte, olumsuzlukları ifade ederek bunlara ilişkin neler yapabileceğini de ifade etmektedir. Ayrıca farkındalık oluşturmada süreç içindekilerin görüşlerinden de yararlandığını dile getirmektedir:

Konuma uygun etkinlik yaparak konumu daha eğlenceli bir hale getirebilirdim. Öğrencilere daha fazla sorular yöneltip onlarla daha fazla etkileşime geçebilirdim. Konuyu anlatırken sabit durmak yerine sınıf içerisinde hareket edebilirdim. Hem benim açısından hem de onlar açısından ders daha dikkat çekici olabilirdi. Derste kullandığım günlük hayattan örneklerin bazılarını resimlerle destekleyebilirdim. Ders sonrasında yaptığım yanlışları düşünerek, görüşler alarak tespit ettim. (K13)

\section{SONUÇ, TARTIŞMA VE ÖNERILER}

30 katılımcı ile gerçekleştirilen bu çalışmada öğretmen adaylarının oluşturdukları yansıtıcı günlükler, öğretmen adaylarının kendi öğretme süreçlerine yönelik farkındalıkları bakımından incelenmiştir. Günlüklerin içeriğine yönelik yapılan değerlendirme sonucunda katılımcıların, öğretme sürecine ilişkin farkındalıklarının oldukça düşük olduğu belirlenmiştir. Elbette bu sonuçta adayların tecrübelerinin yeni oluşmaya başlamasının da etkisi vardır ancak yapılacak mesleğin nitelikleri göz önüne alındığında bu sonucun oldukça çarpıcı olduğu söylenebilir. Öğretmen farkındalığı aynı zamanda öz değerlendirme olarak da ele alınabilir. Bu şekilde ele alındığında da katılımcıların kendilerine ilişkin değerlendirme yapmaktan uzak olduğu dile getirilebilir. Aldıkları teorik dersleri, uygulama boyutuna taşımakta zorlandıkları şeklinde bir yorum, bu noktada yapılabilir.

Öğretmen adaylarını farklı açılardan değerlendiren çalışmalar literatürde mevcuttur ancak yansıtıcı günlükler yardımıyla bir öz değerlendirmede bulundukları çalışma sayısı sınırlıdır. Ussher ve Chalmers (2011), öğretmen adaylarının yansıtıcı günlüklerini çok yönlülük bakımından ele almışlardır ve çalışma sonucunda katılımcıların çok azının çok yönlü günlük oluşturabildikleri tespit edilmiştir. Yeşilbursa (2011) da yaptığı araştırmada öğretmen adaylarının yansıtıcı günlüklerinin yansıtmadan uzak olduğu sonucuna ulaşmıştır. Duban ve Yanpar Yelken'in (2010) çalışmalarında ulaştığı sonuç ise oldukça dikkat çekicidir; araştırmacılar öğretmen adaylarının yansıtıcı öğretmen eğilimi gösterdiklerini tespit etmişlerdir. Ulaşılan bulgunun bu araştırmanın verileri ile örtüşmemesinin sebebi; fakülte değişkeni ile ilişkilendirilebilir. Duban ve Yanpar Yelken'in (2010) çalışmaları, eğitim fakültesi öğrencilerini kapsarken bu çalışma, fen edebiyat fakültelerindeki okuyan ve formasyon sertifika programına devam eden öğrencilerle gerçekleştirilmiştir. Şahin (2009) fen bilgisi öğretmen adaylarıyla 
gerçekleştirdiği çalışmada katılımcıların daha çok tanımlayıcı yansıtıcı düşünme yeteneklerinin ön planda olduğunu, diğer düzeyleri yerine getirmede zorlandıklarını belirlemiştir. El-Dib (2007) Ingilizce öğretmeni adaylarıyla yürüttüğü araştırmasında katılımcıların yarısından çoğunun yansıtma seviyelerinin düşük veya düşük-orta seviyede olduğu tespitinde bulunmuştur. Sıralanan araştırma sonuçları ile bu çalışmanın sonucu arasında paralellik olduğu söylenebilir.

Tok (2008), öğretmen adaylarıyla gerçekleştirilen yansıtıcı düşünme etkinliklerinin adayların kendilerine yönelik farkındalık düzeylerini anlamlı yönde etkilediği gibi öğretmenlik mesleğine karşı da olumlu tutum geliştirmelerine yardımcı olduğunu ifade etmektedir. Dolayısıyla yansıtıcı günlükler özellikle uygulamayı kapsayan dersler boyutunda öğretmen adaylarına kullandırılmalı, konuyla ilgili gerekli yönlendirmeler öğretim üyeleri tarafından yapılmalıdır.

Bu çalışma pedogojikformasyon eğitimi alan öğretmen adaylarıyla gerçekleştirilmiştir. Dolayısıyla katılımcıların meslekî derslere aşinalığı ve yeterliliği konusundaki süre dikkate alındığında birtakım soru işaretlerinin oluşması doğaldır. Çalışmanın eğitim fakültesi öğrencileri ile tekrarlanması öğretmenlik mesleğine yaklaşımın da ortaya konması bakımından önemli görülmektedir.

\section{KAYNAKLAR}

Atay, D. Y. (2003). Öğretmen eğitiminin değişsen yüzü. Ankara: Nobel Yayın Dağıtım.

Akkoyunlu, B., Telli, E., Çetin, M. N. ve Dağhan, G. (2016). Öğretmeneğitiminde yansıtıcıgünlüklereilişkinöğretmen adaylarının görüşleri. Turkish Online Journal of Qualitativelnquiry (TOJQI). 7 (4), 312-330.

Duban, N. ve Yanpar Yelken, T. (2010). Öğretmen adaylarının yansıtıcı düşünme eğilimleri ve yansıtıcı öğretmen özellikleriyle ilgili görüşleri. Çukurova Üniversitesi Sosyal Bilimler Enstitüsü Dergisi. 19 (2), 343 - 360.

Duman, B. (2012). Neden beyin temelli öğrenme?. Ankara: PegemA Yayınları.

El-Dib, M. A. B. (2007). Levels of reflection in actionresearch: An overviewand an assessmenttool. TeachingandTeacherEducation. 23, 24-35.

Ersözlü, Z. N. (2008). Yansıtıcı düşünmeyi geliştirici etkinliklerin ilköğretim 5. sınıf öğrencilerinin sosyal bilgiler dersindeki akademik başarılarına ve tutumlarına etkisi. (Yayınlanmamış Doktora Tezi). Fırat Üniversitesi, Elazığ.

Kızılkaya, G. ve Aşkar, P. (2009). Problem çözmeye yönelik yansıtıcı düşünme becerisi ölçeğinin geliştirilmesi. Eğitim ve Bilim. 34 (154), 82-92.

Malthouse, R. ve Roffey B. J. (2013). Reflectivepractice in educationandtraining. London: Sage Publications.

Melanlığlu, D. ve Demir, T. (2016). Türkçe Öğrenen Yabancılar Örneğinde Yansıtıcı Günlük Kullanma ve Yazma Öz-Yeterliği Arasındaki îlişki. Mustafa Kemal Üniversitesi Sosyal Bilimler Enstitüsü Dergisi, 13 (35).

Millî Eğitim Bakanlığı Talim Terbiye Kurulu Başkanlığı. (2007). Illköğretim düşünme eğitimi dersi ögretim programı (6, 7 ve 8. Sınıf). Ankara.

Moon, J. (2009). Theuse of graduatedscenariostofacilitatethelearning of complexanddifficulttodescribeconcepts. Art, Design \&Communication in HigherEducation. 8 (1), 57-70. 
Nakip, C. (2015). Öğretmen adaylarının öğretmenlik mesleğine yönelik öz-yeterlik inançları ile öğretmenlik mesleğine yönelik tutumları arasındaki ilişki. (Yayımlanmamış Yüksek Lisans Tezi). Abant İzzet Baysal Üniversitesi, Bolu.

Nayır, F ve Ş, Çınkır (2014). Uygulama öğretmenleri, yöneticileri ve pedagojik formasyon öğrencilerinin okullarda öğretmenlik uygulamasında karşılaştıkları sorunlar ve çözüm önerileri. Uluslararası Eğitim Programları ve Öğretim Çalışmaları Dergisi. 4 (7).

Raw, J.,Brigden, D. ve Gupta, R. (2005). Reflectivediaries in medicalpractice. ReflectivePractice. $6(1), 165-169$.

Sarıtaş, M. (2007). Okul deneyimi I uygulamasının aday öğretmenlere sağladığı yararlar konusundaki görüşlerin değerlendirilmesi. Eğitim Fakültesi Dergisi. 20 (1), 121-143.

Şahin, Ç. (2009). Fen bilgisi öğretmen adaylarının yansıtıcı düşünme yeteneklerine göre günlüklerinin incelenmesi. Hacettepe Üniversitesi Eğitim Fakültesi Dergisi. 36, 225-236.

Tok, Ş. (2008). Yansıtıcı düşünmeyi geliştirici etkinliklerin öğretmen adaylarının öğretmenlik mesleğine yönelik tutumlarına, performanslarına ve yansıtmalarına etkisi. Eğitim ve Bilim. 33 (149). 104-117.

Uslu, H. (2009). Altıncı ve yedinci sınıf fen ve matematik derslerinde günlüklerin kullanılmasına yönelik öğrenci görüşlerinin belirlenmesi. (Yayımlanmamış Yüksek Lisans Tezi). Süleyman Demirel Üniversitesi, Isparta.

Ussher, B. ve Chalmers, J. (2011). Nowwhat? First yearstudentteachers' reflectivejournalwriting. WaikatoJournal of Education, 16 (3), 95-110.

Ünver, G. (2016). Türkiye'deki hizmet öncesi öğretmen eğitiminde kuram-uygulama bağlantısı. Yükseköğretim ve Bilim Dergisi. (6) 1, 61-70

Yeşilbursa, A. (2011). Reflection at theinterface of theoryandpractice: An analysis of preservice englishlanguageteachers' writtenreflections. AustralianJournal of TeacherEducation. 36, 104-116.

Yıldırım, A. ve Şimşek, H. (2008). Sosyal bilimlerde nitel araştırma yöntemleri. Ankara: Seçkin Yayınevi.

YÖK. (2015). Pedagojik formasyoneğitimi sertifika programları hakkında açıklama. Retrievedfrom/19836547/Pedagojik_Formasyon_Egitimi_Sertifika_Programlari_Hakkinda"http ://yok.gov.tr/document/HYPERLINK" (Erişim Tarihi: 01.04.2017) 


\section{SUMMARY}

Teacher candidates should be supported with both theoretical and applied courses in their journey to discover their professional competence. One way to follow this recommendation is to use diaries supporting creative and critical thinking. These diaries will serve as a guide in determining what they did and did not both in learning and teaching processes. The fact that the Teaching Practice course is an experience learning and sharing process furthers the importance of ensuring the use of this type of diaries. They serve as a strategic tool in teacher candidates' interpretion of their strong and weak attributes during the practice.

Content analysis was employed to analyze the collected data. The texts collected from the participants were examined based not on their scorings but on certain themes and criteria. According to the instructions created within this context, each student text was first separately evaluated by two experts in the field. Then, the decisions of both experts on to which extent the textual acts were actualized to elaborate the consistency of the texts were compared to each other, which revealed that the evaluations of the experts were in agreement with each other. This is indicative of the consistency between two experts and therefore, of the reliability of the evaluations.

Reflective diaries were analyzed considering teachers' awareness of their own teaching processes. The evaluation of the contents of the diaries revealed that the awareness of the participants towards the teaching process was considerably low. This, of course, to a certain extent, stemmed from the fact that the candidates just recently began to gain experience; but considering the qualities of the profession, this result is undoubtedly quite striking. Teacher awareness can also be regarded as selfevaluation and if we were to view the results from this point of view, we can say that the participants were far away from achieving self-evaluation. At this point, we can reach to the assertion that they struggled to put the theoretical courses they received into practice.

Although the relevant scientific literature offers several studies that evaluate teachers based on different aspects, the number of the studies regarding the self-assessment of teachers with the help of reflective diaries is limited. Some researches focusing on the same subject were reviewed. The results of the examined studies are in agreement with the results obtained in this study.

This study was carried out with teacher candidates who were receiving pedagogical formation. Therefore, considering the time spent to establish familiarity and competence in professional courses, it is only natural that certain aspects of the subject remain curious. Repeating the study with education faculty students is of great importance in revealing the approach to the teaching profession. 